https://doi.org/10.48009/2_iis_2009_355-363

\title{
THE INFORMATION SYSTEMS ANALYST EXAM AS A PROGRAM ASSESSMENT TOOL: PRE-POST TESTS AND COMPARISON TO THE MAJOR FIELD TEST
}

\author{
Donald A. Carpenter, Mesa State College, dcarpent@mesastate.edu \\ Morgan K. Bridge, Mesa State College, mbridge@mesastate.edu \\ Johnny Snyder, Mesa State College, josnyder@mesastate.edu \\ Gayla Jo Slauson, Mesa State College, gslauson@mesastate.edu
}

\begin{abstract}
This paper describes a pre-post test study using the Information Systems Analyst (ISA) exam at a small college. It shows the exam appears to measure CIS learning and also appears to be comparable to the Major Field Test (MFT) in Business in terms of how it assesses. Thus the ISA exam arguably should be considered on an equivalent footing as the MFT, in terms of program assessment. The article advocates that the Institute for Certification of Computer Professionals ICCP conduct further research on a broader scale so that users of the ISA exam can count on its relevance as a program assessment tool.
\end{abstract}

Keywords: Assessment, Information Systems Analyst (ISA), Major Field Test (MFT)

\section{INTRODUCTION}

Program assessment is critical to prove the quality of the program in order to insure preparation of program graduates. There are many choices for when and how to assess, including use of standardized objective tests at the end of the program of study. One such tool for computer information systems programs is the Information Systems Analyst (ISA) Examination.

There is little evidence in the literature as to the appropriateness of the ISA exam or of its acceptance by administration. This paper describes a pre-post test study using the ISA exam at a small college. It attempts to determine whether the ISA exam indeed measures IS learning. It also attempts to determine whether the ISA exam is comparable to the Major Field Test (MFT) in Business in terms of how it assesses learning. If the ISA exam does truly measure IS learning and if it is similar in its measuring to the MFT exam, then the ISA could legitimately be used as a program assessment tool.

The first section below examines the literature relevant to program assessment. The following section of this paper describes the use of the ISA exam in one college and the data collected.
Subsequent sections explain the methods used to examine those data and findings. Lastly, conclusions, limitations and recommendations are discussed.

\section{LITERATURE REVIEW}

Academic program assessment is required for continuous improvement as well as to provide evidence of program quality to accrediting bodies and campus administration [1]. Program assessment is critical to measure the contribution the program makes to students' learning as they progress through the program and to insure quality of graduates. Indeed, "...the ultimate emphasis of assessment is on programs rather than individual students." [16, p. 5].

There are varieties of assessment methods and tools suggested in the literature, thus the importance of choosing wisely. While some individual institutions might prescribe specific tools that must be used by all programs, accrediting associations typically do not [1]. Each program's faculty should choose the methods that are most effective for its program. There are many suggestions in the literature.

There are many choices for when and where to assess. Cunningham \& Omaoayole [5] advocate a course-centered approach based on the syllabus. Moberg \& Walton [15] recommend a multiple occasions approach throughout the major. Payne, Whitfield \& Flynn [18] support a stakeholder approach in the capstone course.

Similarly there are several choices for what to assess. Examining critical incidents throughout the program is suggested by Bycio \& Allen [4]. Evaluations by students' peers are supported by Aurand \& Wakefield [2]. Measuring required student competencies in the major is the method proposed by Roberson et al [19].

There is strong support for a multifaceted approach to assessment [21]. Mirchandani, Lynch \& Hamilton [14] suggest use of Educational Testing Service's (ETS) Major Field Test (MFT) [8] and students' grade point averages. Palomba \& Palomba [17] 
recommend several tools, such as cases, problem sets, pre-post tests, alumni surveys, embedded course assessments, graduating senior surveys and taped presentations in capstone courses. Dyke \& Williams [7] stress the need to gather information from graduates and their employers.

There also is a strong case made in the literature for the use of specific objective test questions to assess student outcomes relative to required competencies [3]. In particular, standardized tests such as the Major Field Test are strongly supported [3, 11, 13, 14].

While the MFT in business measures the learning in the core business curriculum, it does not specifically measure knowledge in computer information systems. The Institute for Certification of Computer Professionals (ICCP) [9] has developed the Information System Analyst (ISA) Exam "for graduating seniors from four year undergraduate Information Systems degree programs, especially for those universities following the Information Systems Model Curriculum.” [6]

A recent issue of the Journal of Information Systems Education focused on IS Education Assessment. Articles within that special issue mentioned the ISA Exam as a means of assessment [10, 12, 20]. However, none of those provided data as to the effectiveness of the ISA Exam and none spoke to the use of the ISA Exam as a program assessment tool, rather than just an individual success measurement.

Moreover, searches on EBSCOHost, Academic Search Premier, Business Source Premier, and Google Scholar for "information systems analyst exam" or "ISA exam" did not return any pertinent results. Consequently, the conclusion is that there is not as widespread published support for the fairly new ISA as a program assessment tool as there is for the decades old MFT.

\section{BACKGROUND}

Assessment policy in a small western state college requires each academic program to be assessed over three "intended education outcomes" with each of those having two "means of assessment." The Computer Information Systems Program in that college has chosen six intended educational outcomes and a total of sixteen means of assessment. The intended educational outcomes address CIS knowledge, business knowledge, critical/analytical skills, oral/written communications skills, project management/teamwork skills, and professionalism.
The sixteen means of assessment include the ISA exam, the MFT exam, capstone projects and presentations, and surveys of students, alumni, employers, and industry advisors. The MFT is an appropriate assessment tool as the BS in CIS includes 27 hours of business courses in addition to 33 hours of CIS courses. The required business courses are, for the most part, the same as required in the core of the BBA program. Arguably, the information technology subscale of the MFT would be a better measure than the full MFT score. However, the subject institution did not have that subscale available.

This CIS program has used the ISA exam from 2003 through 2007. In the first two years, the exam was in the beta test version. Indeed, the faculty of this program contributed several questions to the exam and reviewed numerous other questions. In return for that participation, the exam was free for 2003 and 2004. Since then, this CIS faculty has continued to participate in the creation and review of exam questions.

Because use of the ISA exam was free to the subject college, CIS students in this program were encouraged to take the exam in both their junior and senior years. Four students also took the exam in their sophomore year. After there was a charge for the exam, in 2005 and 2006, only seniors took the exam in the capstone course. In 2007, none of the students who had taken the exam as seniors had taken it previously.

Consequently, the authors have access to data that can be examined in a pre-test, post-test manner to determine whether the ISA exam actually measures increased CIS knowledge from the first to the second time the exam was taken. The authors also have access to MFT scores which can be used to compare whether the ISA and MFT assess in the same manner.

\section{RESEARCH METHODOLOGY}

The concern explored by this article is whether the ISA exam is as valid a tool for information systems program assessment as the MFT exam is for business program assessment. Does the ISA exam measure CIS learning as determined by a pre-test, post-test experiment? If so, the ISA exam could more legitimately be used as an assessment tool. Does the ISA exam measure CIS learning in the same manner in which the MFT measures business learning? If so, the ISA should be given the same credibility as the MFT as an assessment tool. 
The overriding research question is then: Does the ISA exam measure student learning in IS? The research hypotheses to be tested are:

$\mathrm{H}_{1}$ : Taking the ISA exam twice with IS coursework in the interim shows an increase in learning.

$\mathrm{H}_{2}$ : The ISA exam measures learning in the same way as does the MFT.

$\mathrm{H}_{3}$ : The ISA exam measures knowledge consistently from year to year.

$\mathrm{H}_{4}$ : There is student-based variability in ISA scores.

$\mathrm{H}_{5}$ : ISA scores do not differ by students' gender.

$\mathrm{H}_{6}$ : Variability of ISA scores is consistent across the range of scores.

From 2003 through 2007, eighty-six (86) distinct computer information systems students at the subject college took the ISA exam and fifty-one (51) of those took the MFT exam. Thirty-five (35) of those students took the ISA exam twice. Four students took the ISA only as a pre-test as they have not yet taken the test as a requirement in their final semester in the program. Subjects' percentile rankings for the ISA and MFT exams are illustrated in Figure 1 in the Appendix.

The data for the study were gleaned from the reports provided to the college by the Center for Computing Education Research (CCER) for the ISA exam and from Educational Testing Service (ETS) for the MFT exam. Data were entered into and analyzed within both Microsoft Excel 2003 and into SPSS 14.0 for Windows. All statistical tests reported below were run at the $95 \%$ confidence level.

\section{FINDINGS}

Several interesting questions/hypotheses were posed and tested as discussed in the following paragraphs.

\section{$\mathbf{H}_{1}$}

The first question of interest was whether taking the ISA multiple times, with IS coursework between those times, improved students scores and percentiles from the first time to the last, i.e., does the ISA measure CIS learning as determined from a pre-test, post-test experiment. A corresponding hypothesis to reject would be: the mean scores and mean percentiles were equal for the first and second times the ISA was taken. Two paired samples t tests were run for the 35 students who took the ISA exam twice.

The results indicate the mean ISA exam scores were larger for the second time the 35 students took the ISA exam versus the first time the same students took the ISA exam, but not statistically significantly so. However, the mean of the percentiles of the ISA scores is statistically significantly greater for the second time students took the ISA exam versus the first time they took the ISA exam. The supporting statistical data are shown in Table 1 as pairs 1 and 2 .

Table 1: Paired Samples T-Tests for ISA Exam Pre Test and Post Test

\begin{tabular}{|c|c|c|c|c|c|c|}
\hline \multirow[b]{2}{*}{ 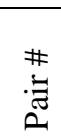 } & \multirow[b]{2}{*}{ Factors } & \multicolumn{3}{|c|}{ Individual } & \multicolumn{2}{|c|}{ Paired } \\
\hline & & Mean & $\begin{array}{l}\text { Std. } \\
\text { Dev. }\end{array}$ & $\mathrm{N}$ & $\mathrm{t}$ & Sig. \\
\hline \multirow{2}{*}{1} & $\begin{array}{l}\text { First } \\
\text { ISA } \\
\text { score }\end{array}$ & 52.02 & 9.458 & 35 & \multirow{2}{*}{ 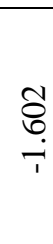 } & \multirow{2}{*}{$\stackrel{\infty}{=}$} \\
\hline & $\begin{array}{l}\text { Last } \\
\text { ISA } \\
\text { score }\end{array}$ & 54.21 & 10.184 & 35 & & \\
\hline \multirow{2}{*}{2} & $\begin{array}{l}\text { First } \\
\text { ISA } \\
\text { percen- } \\
\text { tile }\end{array}$ & 53.60 & 24.607 & 35 & \multirow{2}{*}{ 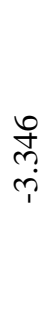 } & \multirow{2}{*}{ ชิ } \\
\hline & $\begin{array}{l}\text { Last } \\
\text { ISA } \\
\text { percen- } \\
\text { tile }\end{array}$ & 62.60 & 26.212 & 35 & & \\
\hline
\end{tabular}

Since the means of the scores and percentiles are larger for post tests versus the pre tests, the conclusion is that taking the ISA at least twice does indeed improve students' scores. From a program assessment perspective, the assumption is that during the lag (typically a year) between the first and second takings of the ISA exam, students completed several additional computer information systems courses. Therefore, the program added that value to the students' knowledge levels and the ISA exam measured that value.

However, further consideration is in order since the increase in mean raw scores is not statistically significant, even though the increase in mean percentile scores is significant. These authors assume that discrepancy can be explained by the deliberate strengthening in the ISA exam that occurred in the timeframe of much of the pre test and post test period of this study (i.e., 2003-2006). That would cause the test to be more difficult, thereby suppressing the mean raw score of the post test takers. Conversely, 
the significant increase in the mean percentile score between pre and post tests is an indication that the students in question gained knowledge between preand post tests, by comparison to the national group of exam takers.

There was one additional important behavioral factor available to consider, namely whether the students who took the ISA at least twice fared better on their last attempt than those who only took the test once. Since the difference in mean percentiles proved to be statistically significant in the previous tests, the mean percentiles were used to test this question, rather than using the mean raw scores.

The hypothesis to consider is that the mean percentiles of the two groups are equal. Specifically, is the mean ISA percentile score of the 47 students who only took the exam once equal to the mean ISA percentiles on the last attempt of those 35 students who took the exam more than once? An independent samples t test (see Table 2) yielded a $t$ value of .901 , causing the authors to fail to reject the notion that the mean scores of the two groups are equal.

Table 2: Independent Samples T-Test for OneTime ISA Exam Takers vs Two-Time ISA Exam Takers

\begin{tabular}{|c|c|c|c|c|c|}
\hline \multirow[b]{2}{*}{ Factors } & \multicolumn{3}{|c|}{ Individual } & \multicolumn{2}{|c|}{ Paired } \\
\hline & Mean & $\begin{array}{l}\text { Std. } \\
\text { Dev. }\end{array}$ & $\mathrm{N}$ & $\mathrm{t}$ & Sig. \\
\hline $\begin{array}{l}\text { Mean ISA } \\
\text { percentile } \\
\text { score for } \\
\text { one-time } \\
\text { exam takers }\end{array}$ & 57.47 & 24.970 & 47 & \multirow{2}{*}{ ఠ̊ } & \multirow{2}{*}{$\frac{?}{n}$} \\
\hline $\begin{array}{l}\text { Mean ISA } \\
\text { percentile } \\
\text { score for } \\
\text { two-time } \\
\text { exam takers }\end{array}$ & 62.60 & 26.212 & 35 & & \\
\hline
\end{tabular}

So, those who chose to take the ISA exam only once fared equally well as those who took the exam multiple times, although (as discussed above) those who took the exam multiple times benefited from doing so. A conclusion might be that those who chose to take the exam multiple times were wise to do so as it improved their scores.

However, from a program assessment perspective, it is equally easy to grasp the assumption that it was the additional coursework that the students took between their sittings for the ISA exam that made the difference in their scores. This reinforces the notion claimed above that taking additional CIS courses did indeed increase students' knowledge levels and that the ISA exam does indeed measures that increase. The authors hasten to remind the reader that those are still assumptions, however.

$\mathbf{H}_{2}$

The second major research question is whether CIS students' scores on the ISA exam taken in the last semester of their senior year mirrored the scores on the MFT, typically taken in the same semester. The hypothesis to consider for this is that the mean percentiles are equal for the ISA and the MFT. The $\mathrm{t}$-value of the paired samples $\mathrm{t}$ test was -.618 and the significance was .539 (see Table 3). Thus, there is not enough statistical evidence to reject the null, indicating that students percentile scores are equal on the last ISA and the MFT.

Table 3: Paired Sample T-Tests for ISA Exam Percentile Scores vs MFT Percentile Scores

\begin{tabular}{|c|c|c|c|c|c|c|}
\hline \multirow[b]{2}{*}{$\begin{array}{l}\# \\
: \Xi \\
\tilde{\sigma}\end{array}$} & \multirow[b]{2}{*}{ Factors } & \multicolumn{3}{|c|}{ Individual } & \multicolumn{2}{|c|}{ Paired } \\
\hline & & Mean & $\begin{array}{l}\text { Std. } \\
\text { Dev. }\end{array}$ & $\mathrm{N}$ & $\mathrm{T}$ & Sig. \\
\hline \multirow[t]{2}{*}{3} & $\begin{array}{l}\text { Last } \\
\text { ISA } \\
\text { percen- } \\
\text { tile }\end{array}$ & 59.45 & 24.727 & 51 & \multirow{2}{*}{$\frac{\infty}{b}$} & \multirow{2}{*}{ ले } \\
\hline & $\begin{array}{l}\text { MFT } \\
\text { percen- } \\
\text { tile }\end{array}$ & 60.90 & 25.006 & 51 & & \\
\hline
\end{tabular}

The assumption is that the means are equal between the ISA and MFT tests. That might also say that the ISA and MFT have equal value in terms of their usability as valid measurements for assessment purposes. While this is an assumption at this point in time, this is an important consideration as the MFT has a longer history, a wider audience, and arguably greater support among administrators. Showing the comparison between the ISA and MFT could increase support for the ISA as an assessment instrument.

$\mathbf{H}_{3}$

Another consideration is whether the students' mean ISA raw scores vary by year. The hypothesis would be that they are equal. Table 4 presents the results of a one-way ANOVA for that data. An overall F score of 7.314 and a significance level of .000 give cause to reject the hypothesis, meaning the scores are not equal across all five years. A Tukey post hoc analysis shows the difference is significant for four of ten 
selected year comparisons, as shown in Table 4. This causes one to question whether the ISA test questions are balanced in difficulty from one year to the next. This also gives rise to the next question, $\mathrm{H}_{4}$, below.

Table 4. Tukey Post Hoc Analysis of One-Way ANOVA of ISA Raw Scores

\begin{tabular}{|l|l|l|l|l|}
\hline Year 1 & Year 2 & $\begin{array}{l}\text { Mean } \\
\text { Dif. }\end{array}$ & $\begin{array}{l}\text { Std. } \\
\text { Error }\end{array}$ & Sig. \\
\hline 2003 & $2004^{*}$ & 7.914 & 2.531 & 0.020 \\
\hline & $2005^{*}$ & 17.270 & 3.589 & 0.000 \\
\hline & 2006 & 2.241 & 2.696 & 0.920 \\
\hline & 2007 & 2.251 & 3.987 & 0.980 \\
\hline 2004 & 2005 & 9.356 & 3.413 & 0.057 \\
\hline & 2006 & -5.673 & 2.458 & 0.154 \\
\hline & 2007 & -5.664 & 3.831 & 0.579 \\
\hline 2005 & $2006^{*}$ & -15.029 & 3.538 & 0.001 \\
\hline & $2007^{*}$ & -15.020 & 4.598 & 0.014 \\
\hline 2006 & 2007 & 0.009 & 3.942 & 1.000 \\
\hline
\end{tabular}

* Mean difference is significant at .05 level

$\mathbf{H}_{4}$

Given the previous test in $\mathrm{H}_{3}$ that indicates that the means of raw ISA scores are not equal across five years, one does not want to quickly conclude that there is a flaw in the ISA question selection process. While that is a possibility, there is a likelihood that the difference is actually due to the students, holding the curriculum constant. To provide evidence of that, there should be an answer to the question "Is there a difference in MFT scores among the same students?"

Hence a one-way ANOVA was run on the MFT data. It produced an $\mathrm{F}$ value of 5.492 and a significance level of .001. That causes one to reject the hypothesis that the mean MFT percentiles for this set of students are the same from year to year. That also refutes to some degree the previous concern that there might be a flaw in the ISA question selection process from year to year.

\section{$\mathbf{H}_{5}$}

Given the findings from the previous questions - that there is some student-based difference in the year-toyear ISA scores - the authors set about to explore that. Unfortunately, the only demographic data with sufficient number of respondents in each respondent grouping was gender. Consequently, an independent samples t test was run to compare the mean ISA raw score of 54.87 of 49 males to the mean ISA raw score of 53.44 of 33 females. A t score of .684 did not give cause to reject the hypothesis that ISA scores differed by gender.

$\mathbf{H}_{6}$

When considering $\mathrm{H}_{2}$, a plot of the MFT versus ISA percentiles (see Figure 2 in Appendix) raised concern about the variability of the data over the entire range. There appeared to be a different clustering of data points above versus below the levels where the ISA percentile is 63 and the MFT percentile is 71.5 for those who took the ISA as a pre-test versus those who did not. If there is some proven variability, there might be a suggestion of some sort of inequity within the ISA exam. Specifically, the question is whether the mean ISA percentiles for the two groups of points above those levels are equal for the two groups of points and whether the mean ISA percentiles for the two groups below those levels are equal. The two hypotheses to consider are that means of the pairs of groups are equal.

Two independent samples t tests were performed, with the results reported in Table 5. The low $t$ values (.292 and .167) do not yield enough evidence to reject the hypotheses claiming the means of the two groups are the same below and above the level where the ISA percentile is 63 .

However, as indicated by the standard deviations, there is an obvious difference in the variability the higher ISA percentiles versus the lower ISA percentiles. Similarly, there is a lower standard deviation in the lower percentiles for those who took the ISA exam as a pre-test versus those who did not. This could suggest that taking the ISA exam twice reduced the variability in scores. However, the only real conclusion that can be drawn is this aspect of the data should be examined in more depth over larger sample sizes.

Table 5. Independent Sample T-Test Results of ISA Percentile Scores Above and Below 63 vs Whether the Students Took the Exam Twice

\begin{tabular}{|c|c|c|c|c|c|c|}
\hline \multirow{2}{*}{$\begin{array}{l}\text { ISA > } \\
63 ?\end{array}$} & \multirow{2}{*}{$\begin{array}{l}\text { Pre- } \\
\text { test? }\end{array}$} & \multirow{2}{*}{$\mathrm{N}$} & \multirow{2}{*}{ Mean } & \multirow{2}{*}{$\begin{array}{l}\text { Std. } \\
\text { Dev. }\end{array}$} & \multicolumn{2}{|c|}{ Pair } \\
\hline & & & & & $\mathrm{t}$ & Sig \\
\hline No & Yes & 27 & 39.56 & 15.072 & \multirow{2}{*}{ ָิ } & \multirow{2}{*}{$\begin{array}{l}\infty \\
\infty \\
\infty\end{array}$} \\
\hline No & No & 15 & 38.00 & 18.925 & & \\
\hline Yes & Yes & 20 & 81.65 & 11.278 & \multirow{2}{*}{$\hat{6}$} & \multirow{2}{*}{$\stackrel{N}{\stackrel{N}{~}}$} \\
\hline Yes & No & 20 & 81.05 & 11.381 & & \\
\hline
\end{tabular}




\section{LIMITATIONS}

There are three substantial limitations to this research. One is in the number of students who took the test. While the count was large enough to justify the statistics used, and certainly to describe the local subjects, it is not large enough to draw conclusions about all students who have taken the ISA exam. The data in this paper accurately describes one set of students, but one might not be able to infer the same findings to a larger population.

A second limitation is in the nature of the ISA exam takers in this study and in the way the exam is administered. The subject college has moderately selective enrollments. As a result, the CIS faculty has determined the program goal as follows: the mean of the local CIS students' ISA raw scores will exceed the national average mean raw score. The local students have exceeded that benchmark each of the five years. However, that is not an indication that the program has contributed to an increase in their CIS knowledge level as they progress through the CIS program. The pre-post test model seemed to show that increase, but present policy prohibits continuing use of the ISA exam as a pre-test.

The third limitation is the use of percentiles in this research. The reported percentiles for both the ISA exam and the MFT are for the particular year in which the student took the test. As such, comparing percentiles from one year to the next are less meaningful than if the percentiles were for all students who have ever taken the exam. Similarly, comparing percentiles from one test to the other has questionable value. The manner in which the comparisons are used herein is useful as long as the reader understands that limitation.

\section{CONCLUSIONS AND RECOMMENDATIONS}

The authors are sufficiently persuaded that the ISA might indeed measure student learning through the student's time in the CIS program. The pre-test percentiles of thirty-five students who took the exam in the spring of their junior year were significantly lower than their scores when they took the exam in the spring of their senior year. Therefore, it is suggested that the ISA exam might indeed be a valid tool for computer information systems program assessment.

There is also significant evidence to begin to lay claim that the ISA exam should be considered on the same par for CIS program assessment as the MFT exam is for business program assessment. The mean percentiles of fifty-one students who took the MFT were similar to the mean percentiles of their scores on the ISA exam. Consequently, the ISA exam should be supported by administration as a valid CIS program assessment tool. While the ISA exam does not measure program quality per se, measurement of student learning in the program, as opposed to learning within individual courses, is one component of a multi-faceted program assessment plan.

Nothing was found to indicate the ISA exam is gender-biased. There are differences in ISA raw scores from one year to the next, but those can be attributed to variability in the students who took the exam. There is some difference in the distribution of scores for those whose percentile on the ISA was higher than 63 versus those 63 or lower. However, the means of those scores are the same which indicates no anomaly in the ISA exam regarding factors that cause students to score higher or lower.

This research has raised some interesting questions. Some of those questions could be addressed by replicating the research at the micro levels at other colleges. However, that is possible only if the ISA exam has been taken at least twice by a sufficient number of students who have also taken the MFT. The authors assume such scenarios are rare, as the ISA exam is seen by most people as a student assessment tool rather than as a program assessment tool. Nonetheless if such research could be done, it could validate that the ISA exam does indeed show learning across students' time in CIS programs. As a result, there would be a higher level of comfort that the ISA exam is a relevant assessment tool for CIS programs. Moreover, the acceptance and support of the ISA exam among administrators would increase.

The ultimate logical conclusion is that more research should be conducted at the macro level in order to measure the effectiveness of the ISA Exam as a valid program assessment tool. The organization that has access to all ISA Exam scores is the Center for Computing Education Research (CCER), the group that developed the exam as a measure of individual performance. These authors encourage CCER to conduct such studies.

\section{REFERENCES}

1. Association to Advance Collegiate Schools of Business (AACSB). (2006). Eligibility Procedures and Accreditation Standards for Business Accreditation. Tampa, FL: AACCB. pp. 58-60. 
2. Aurand, T. \& Wakefield, S. (2006). Meeting AACSB assessment requirements through peer evaluations and rankings in a capstone marketing class. Marketing Education Review, 16(1), 4146.

3. Black, H. \& Duhon, D. (2003). Evaluating and improving student achievement in business programs: The effective use of standardized tests. Journal of Education for Business, 79(2), 90-98.

4. Bycio, P. \& Allen, J. (2004). A critical incidents approach to outcomes assessment. Journal of Education for Business, 80(2), 86-92.

5. Cunningham, B. \& Omaoayole, O. (1998). An assessment-oriented syllabus model for business courses. Journal of Education for Business, 73(4), 234-241.

6. CCER. (2007). Center for Computing Education Research web site. Retrieved on December 29, 2007 from www.iseducation.org//isadmin/ ISadminMain.aspx.

7. Dyke, J. \& Williams, G. (1996). Involving graduates and employers in assessment of a technology program. In Banta, T., Lund, J., Black, K., \& Oblander, F. (Ed.), Assessment in practice (pp. 91-101). San Francisco: JosseyBass.

8. ETS. (2007). Educational Testing Service. Retrieved on December 29, 2007 from http://www.ets.org/.

9. ICCP. (2007). Institute for Certification of Computer Professionals. Retrieved on January 8, 2008 from http://www.iccp.org/iccpnew/ index.html\#3

10. Kamoun, F., \& Selim, S. (2008). On the design and development of WEBSEE: A web-based senior exit exam for value-added assessment of a CIS program. Journal of Information Systems Education, 19 (2), 209-222.

11. Karathanos, D. (1991). Outcome measures of collegiate business curricula: A comparison of two instruments. Journal of Education for Business, 67(2), 100-105.

12. Landry, J. P., Saulnier, B. M., Wagner, T. A., \& Longenecker, Jr., H. E. (2008). Why is the learner-centered paradigm so profoundly important for information systems education? Journal of Information Systems Education, 19 (2), 175-179.

13. Manton, E. \& English, D. (2002). College of business and technology's course embedded student outcomes assessment process. College Student Journal, 36(2), 261-169.

14. Mirchandani, D., Lynch, R., \& Hamilton, D. (2001). Using ETS major field test in business: Implications for assessment. Journal of Education for Business, 77(1), 51-60.

15. Moberg, C. \& Walton, J. (2003. Assessment of the Marketing Major: An empirical investigation. Marketing Education Review, 13(1), 70-77.

16. Palomba, C. \& Banta, T. (1999). Assessment essentials: Planning, implementing, and improving assessment in higher education. San Francisco: Jossey-Bass. p. 5.

17. Palomba, N. \& Palomba, C. (1999). AACSB Accreditation and assessment at Ball State University's College of Business. Assessment Update, 11(3), 4-15.

18. Payne, S., Whitfield, M., \& Flynn, J. (2002). Assessing the business capstone course through a method based on the SOTL and the stakeholder process. Journal of Education for Business, 78(2), 69-74.

19. Roberson, M., Carnes, L., \& Vice, J. (2002). Defining and measuring student competencies: A content validation approach for business program outcomes assessment. Delta Pi Epsilon Journal, 44(1), 13-24.

20. Wagner, T. A., Longenecker, Jr., H. E., Landry, J. P., Lusk, C. S., \& Salnier, B. M. (2008). A methodology to assist faculty in developing successful approaches for achieving learner centered information systems curriculum outcomes: Team based methods. Journal of Information Systems Education, 19 (2), 181-195.

21. Young, C. (1996). Triangulated Assessment of the Major. In Banta, T., Lund, J., Black, K., \& Oblander, F. (Ed.), Assessment in practice (pp. 101-104). San Francisco: Jossey-Bass. 


\section{APPENDIX}

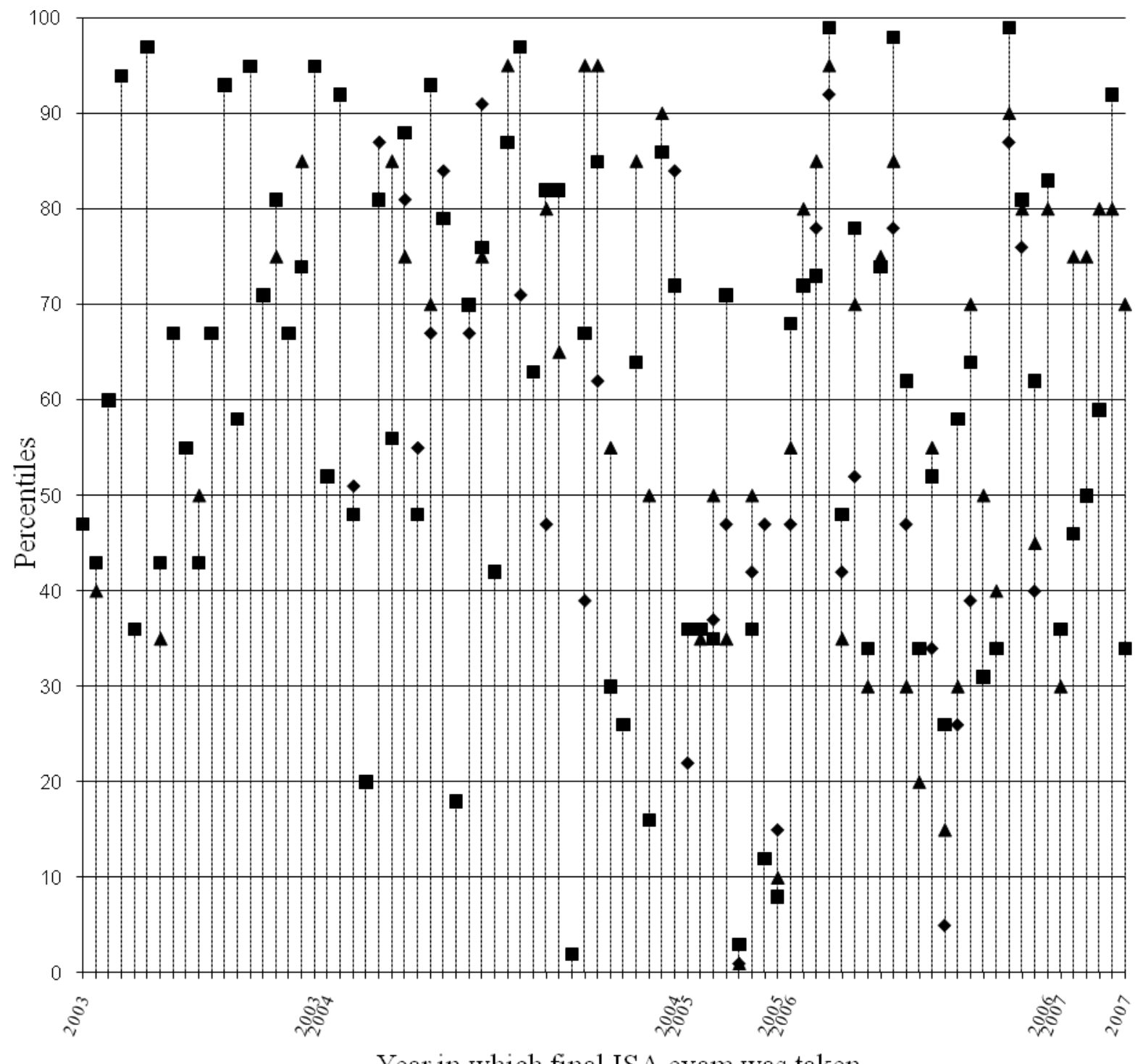

Year in which final ISA exam was taken

- ISA Pre-test percentiles $\quad$ ISA Post-test percentiles $\Delta$ MFT Percentiles

Figure 1: ISA and MFT Test Scores 


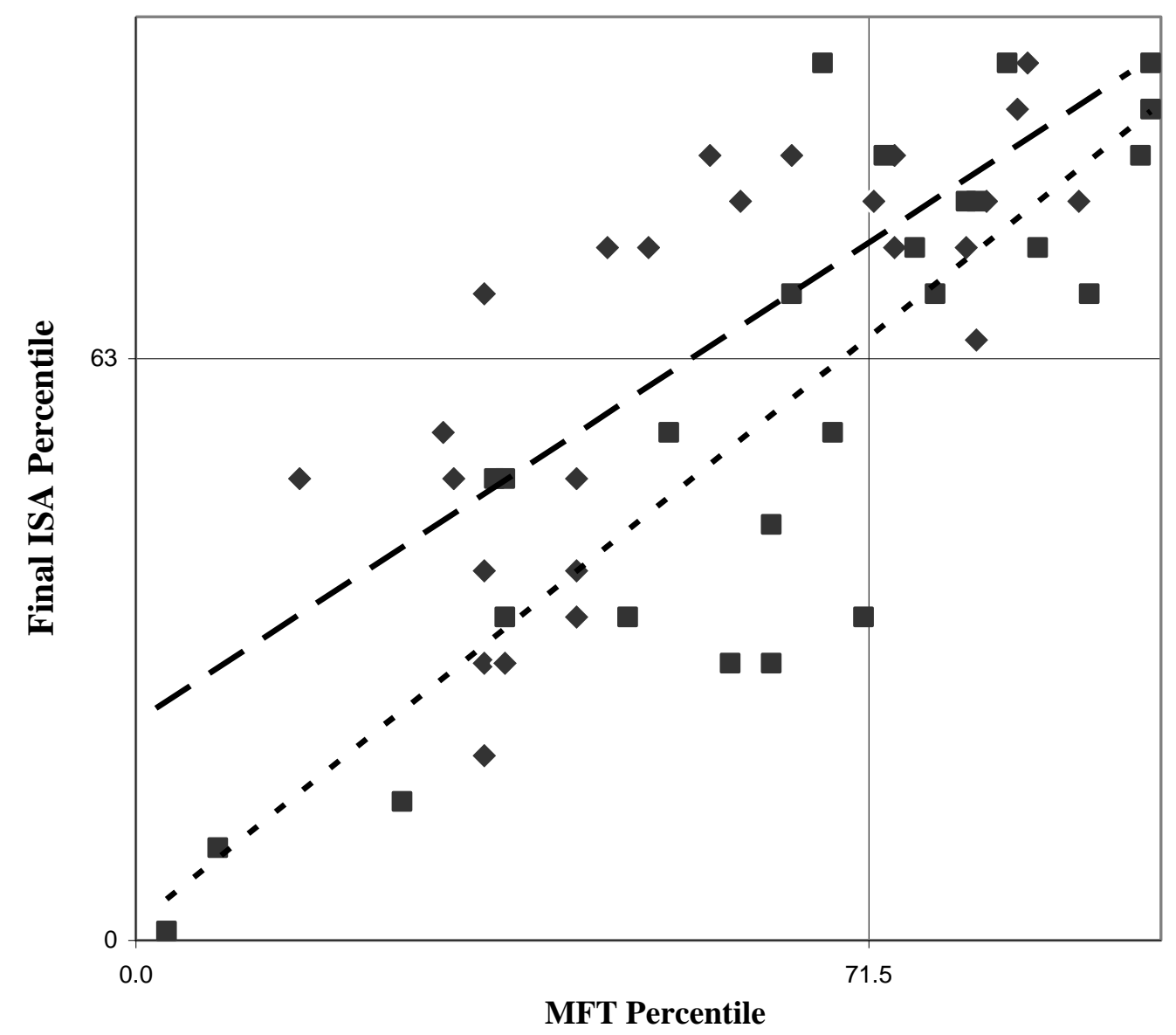

- Did not take ISA pre-test

- Took ISA pre-test

- - Linear (Did not take ISA pre-test)

- - - Linear (Took ISA pre-test)

Figure 2: ISA vs MFT percentiles, segregated by pre-test status 